\title{
Lazer e festas: Estudo sobre os modos de divulgaçáo de bebidas nos campi universitários
}

\author{
Liana Abráo Romera \\ Centro de Educação Física e Desportos, Universidade Federal do Espírito Santo - UFES, Vitória, ES, Brasil
}

\begin{abstract}
Resumo: Este artigo aborda a temática consumo de álcool, ressaltando que estímulos a sua utilização podem ser observados na publicidade e em diferentes contextos. Aqui são destaques os cartazes de festas de campi universitários. As festas universitárias representam uma das inúmeras modalidades de lazer do público jovem; sociabilidade, paquera e diversão são algumas marcas desses contextos festivos. O consumo excessivo de bebidas também se tem tornado parte desse cenário e, por vezes, de forma abusiva. De modo geral, as festas voltadas para esse público são divulgadas com cartazes espalhados pelos campi universitários com o objetivo de convencer esse público à adesão e participação. Com base nos argumentos usados nesse modelo de publicidade, este estudo tem por objetivo verificar os estímulos ao abuso do consumo de bebidas alcoólicas. O estudo descritivo-qualitativo é desenvolvido pela combinação de quadro metodológico, composto de pesquisa bibliográfica e documental, com a análise de 173 cartazes de festas direcionadas ao público jovem, coletados em universidades do interior do estado de São Paulo. As análises apontam para argumentos verbais e imagéticos que estimulam o beber excessivo. A apologia do consumo de bebidas em situação de lazer coloca esse campo de estudo em importante lugar de análise dos comportamentos nele vivenciados, especialmente os de grupos jovens. Os resultados representam importante passo para a compreensão dos novos modos de consumo do álcool, ocupação e vivência do lazer, bem como alertam para o desenvolvimento de programas de prevenção dirigidos ao público e espaços específicos.
\end{abstract}

Palavras-chave: Lazer, Álcool, Controle de Publicidade de Produtos, Juventude.

\section{Leisure and parties: Study on the dissemination of alcoholic drinks on university campuses}

\begin{abstract}
The present study addresses the issue of alcohol consumption, emphasizing that persuasion to consumption can be observed in different contexts through advertising, mainly by posters put up at parties in university campuses. University parties represent one of the numerous forms of leisure of young adults, and sociability, flirt, and entertainment are some marks of these festive contexts. Binge-drinking has also become part of these scenarios, sometimes abusively. Generally, the parties aimed at this public are publicized with posters scattered throughout college campuses in order to convince this public to adhere and participate. This study aimed to verify the persuasion to alcohol abuse, found in fliers and posters disseminating these parties, based on the arguments used. This qualitative descriptive study was developed by combining a methodological framework composed of bibliographic and documental analysis of 173 party posters, aimed at the young public, collected in universities in the state of Sao Paulo. The analysis indicates verbal and imagetic arguments that encourage excessive drinking. The apology to beverage consumption in leisure activities puts this field of study in an important place for analyzing the behaviors experienced in it, especially by youth groups. The results represent an important step for the understanding of new modes of alcohol consumption, occupation and experience of leisure, and alert to the development of prevention programs directed to this public and specific spaces.
\end{abstract}

Keywords: Leisure, Alcohol, Product Publicity Control, Youth.

Autor para correspondência: Liana Abrão Romera, Centro de Educação Física e Desportos, Universidade Federal do Espírito Santo, Avenida Fernando Ferrari, 514, CEP 29705-410, Vitoria, ES, Brasil, e-mail: liromera@uol.com.br

Recebido em 30/8/2013; $1^{\text {a }}$ Revisão em 20/2/2014; Aceito em 4/5/2014. 


\section{Abordagem e consumo}

Este artigo aborda a relação entre a publicidade de cerveja e o lazer, com destaque para cartazes e folders com anúncios de festas cujo público alvo é a juventude, que por meio de propaganda recebe de forma incessante mensagens sugestivas da vinculação entre diversão e consumo de bebidas. Exaustivamente, são empregados recursos publicitários com imagens de festas que trazem cenários de imensa alegria, descontração e socialização, facilmente interpretadas como situaçôes de lazer.

Com o objetivo de estudar a aproximação estabelecida entre o consumo de cerveja e a vivência do lazer, o foco do presente estudo é verificar a existência de estímulos ao abuso do consumo de bebidas alcoólicas nos folders e cartazes de divulgação de grandes festas, entendidos aqui como material de publicidade dos referidos eventos de lazer. O estudo também visa, em última instância, subsidiar políticas focais de prevenção voltadas a espaços e públicos específicos pois, de acordo com Babor et al. (2003), restriçóes a estratégias de persuasão de marketing representam uma das formas de intervenção para a diminuição do consumo do álcool.

O estímulo ao consumo de bebidas implícito nas diferentes publicidades foi tema de estudos de Vendrame e Pinsky (2011), que analisaram a relação entre a propaganda de bebidas alcoólicas e o seu consumo, mostrando que o conteúdo das mensagens publicitárias atua no processo de tomada de decisão do indivíduo para que ele efetive tal consumo.

A abordagem da temática publicidade de cerveja, juventude e lazer não deve ser traduzida como discurso moralista, que apregoa a tolerância zero ao consumo de bebidas, mas sim como a necessidade de provocar o debate e a reflexão acerca de alguns paradoxos que esse cenário impóe.

Pensa-se que tão importante quanto a efetivação da Lei Seca ${ }^{1}$ deveria ser a ampliação da regulamentação da publicidade de cerveja e náo somente na mídia televisiva ou nos espetáculos futebolísticos ${ }^{2}$, mas também nos anúncios e cartazes de promoção de lazer dirigidos de um modo geral à juventude, especificamente aos universitários - considerando que os murais dos campi universitários são repletos de convites para diferentes festas, divulgação publicitária acompanhada da apologia de um grande consumo de bebidas alcoólicas, principalmente a cerveja.

Também é importante comentar que a exaltação da alegria, a diversão e a descontração usadas como recursos de convencimento sáo empregadas de diferentes maneiras em propagandas nas mais diversas mídias, fazendo-se também presente em patrocínio de megaeventos, de times de futebol, da seleção brasileira, além de promover grandes festas e eventos dirigidos ao público jovem.

Para que se entenda um pouco essa exploração da publicidade, precisa-se saber que o hedonismo é a busca do prazer pelo ser humano, que, aliado aos modos de comportamento da atualidade, faz da vivência do lazer, para alguns grupos, um momento apropriado para a experimentação e o uso de substâncias lícitas ou ilícitas e por vezes tal consumo se transforma na própria vivência do lazer.

Apesar disso, a atenção da mídia, de modo geral, apresenta-se consideravelmente voltada para o uso de substâncias ilícitas (maconha, cocaína, crack), náo trazendo à tona o debate sobre os impactos e as consequências negativas referentes ao consumo excessivo de álcool, que é responsável por problemas sociais de grande porte e em número muito maior de consumidores quando feita a comparação com as consequências do uso de drogas ilícitas. Ainda assim, a indústria de bebidas alcoólicas segue como importante financiadora de programas televisivos, sobretudo os esportivos (NOTO et al., 2003).

É necessário que se compreenda o campo de estudos do lazer como espaço de análise dos comportamentos nele vivenciados, considerando ser esse um espaço socialmente permitido para a busca da excitação e do prazer. Essa estreita relação entre lazer e prazer, buscada no tempo disponível, é ressaltada por Romera e Marcellino (2010, p. 82). Os autores afirmam que

Há que se considerar que, entre os aspectos característicos da vivência do tempo disponível, destaca-se a busca pela liberdade, possibilidade de expressão das emoçóes socialmente reprimidas e conquista de prazeres, tornando-se ocasião favorável para a experimentação e uso de drogas lícitas e ilícitas.

Ainda que diferentes estudos - aqui vale citar Bertolo (2011), Dumazedier (2003), Gonzalez e Bueno (2003), Martins et al. (2008), Pinsky (2009), Romera e Reis (2009) - tenham observado o lazer como espaço associado ao uso de drogas, não é recomendado e tampouco produtivo incorrer no reducionismo simplista de atribuir a todo lazer tal possibilidade, pois que a complexidade do tema exige análises mais amplas e profundas.

Seria possível verificar, por esse aspecto, uma sociedade marcada pela associação direta entre consumir e divertir-se, ainda fortalecida pelo imediatismo e excessos, marcas fundantes da modernidade, propagados e legitimados na 
publicidade midiática, que por sua vez aposta no lazer e no consumo como argumentos persuasivos.

Para Lipovetsky (2007, p. 212), entre as marcas da modernidade destaca-se a busca da felicidade pelo hiperconsumo, que assenta suas promessas sobre o prazer/lazer: "[...] da individualização e da comercialização do tempo livre [...] a lógica que triunfa é a do tempo individualista do lazer-consumo". Segundo o filósofo, a sociedade vivencia, a partir das duas últimas décadas, um novo modelo de consumo, inaugurando um terceiro estágio do capitalismo, que ele chama de sociedade do hiperconsumo. Promessas de bem imediato transformam-se em mercadorias de consumo que passam a compor a vida do homem, para o qual a busca do bem-estar tornou-se o novo deus, que tem no consumo o seu templo.

Lipovetsky (2007, p. 173) destaca ainda que

[...] os anúncios exploram temáticas e registros inéditos, que continuam em vigor em nossos dias: elogio da mulher moderna, maquiada e sedutora, culto da autorrealização, do conforto e dos lazeres, sacralizaçáo da juventude.

O hiperconsumo, conforme usado por Lipovetsky, tem refletido um padrão de beber específico, caracterizado pelo "beber excessivo" ou "beber ao extremo", representando a relação que uma parcela da sociedade estabelece com a bebida, preferencialmente em momentos de lazer. "Beber ao extremo" é uma expressão surgida entre os pesquisadores da área, assim como o termo binge, definido como sendo o consumo, em uma só ocasião, de cinco doses ou mais para homens e quatro doses ou mais para mulheres.

Nesse sentido, o hiperconsumo apontado por Lipovetsky (2007) é aplicado também para o consumo de bebidas, representando um comportamento de lazer hedonista, incentivado pela publicidade e pela promoção de festas para o público universitário, conforme aponta o material analisado nesta pesquisa.

Os anseios humanos são apreendidos de modo bastante inteligente pelo universo da publicidade, veiculando - de maneira subliminar - mensagens que associam a vivência do lazer ao consumo de cerveja. A argumentaçáo persuasiva não ocorre necessariamente com a comunicação verbal, mas, invariavelmente, valendo-se de imagens de divertimento, que supóem ludicidade e sociabilidade, elementos comuns ao lazer.

Sentir-se realizado, jubiloso e usufruir de tudo o que proporciona prazer representa, segundo Lipovetsky (2007), a grande e excessiva busca do ser humano na modernidade. E essa busca apreendida pela publicidade é desenvolvida com a atenção voltada exclusivamente para as necessidades e, acima de tudo, para a satisfação do consumidor.

Lipovetsky defende que atender aos prazeres transformou-se na principal motivaçáo para a felicidade. A visibilidade social conquistada pela ostentaçáo do consumo cede lugar ao indivíduo pleno e feliz, fortalecendo a era do bem-estar e da satisfação própria.

Assim, para a criação de uma peça publicitária, devem estar presentes alguns pontos que objetivam atingir o público alvo: despertar atenção, suscitar interesse, provocar desejo, desencadear a ação da compra.

No campo da economia, segundo Nunes Júnior (2001, p. 7),

[...] o termo publicidade traduz a atividade desenvolvida para fomentar o consumo ou para seduzir o consumidor para aquisiçáo de determinados produtos ou serviços.

Desse modo, se a publicidade é comparada à arte de convencer, persuadir e seduzir, pode-se concluir que a publicidade da cerveja tem conseguido atingir seus objetivos, uma vez que é crescente o número de seus consumidores, segundo apontado por Pinsky (2009) e pelas conclusóes apresentadas no II Levantamento Nacional de Álcool e Drogas (LENAD) (INSTITUTO..., 2012).

\section{Cerveja e publicidade}

Com base nas imagens veiculadas pela mídia do consumo de cerveja, em cenários marcados pela descontração em festas, praias, baladas, barzinhos, estádios de futebol, churrascos entre amigos, ou seja, em contextos reconhecidamente de espaços de lazer, vai se estabelecendo uma estreita relação entre duas açôes cada vez mais impressas na percepção de uma parcela da juventude: divertir-se passa a ser sinônimo de beber cerveja, ou somente existe diversão se for acompanhada do consumo de bebidas alcoólicas.

Essa percepção é reforçada pela publicidade da cerveja, na qual se pode observar um desfile de imagens marcadas por belos jovens consumindo a bebida de maneira alegre, em agradável e bem-sucedido contexto de diversão e lazer, especialmente planejados com o intuito de convencer o público-alvo de que cerveja e lazer são componentes inseparáveis e garantia de diversão (BERTOLO; ROMERA, 2011).

Suárez, Tomás e Tomás (2003, p. 9, tradução nossa), ao estudarem uma parcela da populaçáo jovem da Espanha, observam que: 
[...] existe uma centralidade do lazer entre os grupos de jovens; centralidade bem conhecida pelos poderes econômicos e que, sob qualquer circunstância, pode ser evitada. Desse modo, será no lazer que os jovens poderão se sentir realizados, garantindo sua identidade, tanto pessoal como coletiva, pois não devemos esquecer que o jovem realiza sua aprendizagem por meio de um processo condicionado socialmente pela cultura, que em boa medida é uma cultura do lazer, do entretenimento, do desfrute e do consumo.

Essa sociabilidade e valorização do lazer vivenciadas pelos jovens são há muito percebidas pela indústria cultural e do entretenimento, que tem nessa parcela da sociedade um importante número de consumidores de bens e serviços. Não faltam eventos patrocinados pelas cervejarias cujo principal alvo é a juventude.

A Companhia de Bebidas das Américas (AMBEV) integra a maior plataforma de produção e comercialização de cervejas do mundo e patrocina mais de 4 mil eventos em todo o Brasil, que, segundo seus promotores, vão do Carnaval à Vaquejada, criando a conexão entre o público e as marcas presentes na agenda do fim de semana de diferentes regiōes do país.

De acordo com informaçôes colhidas em site oficial, a AMBEV destaca os principais eventos por ela apoiados, confirmando seu interesse pela relação com o lazer e a juventude, tomada como importante recurso de convencimento do consumidor alvo:

Apoiamos eventos de diversos perfis e para diferentes públicos em várias plataformas: Country, Eletrônico, Folia, Junina, Músicas Tradicionais, Premium, Sertanejo, Universitário, Surf, Forró, Samba e Vaquejada, entre outros. Contribuímos na viabilização de eventos em todas as regióes brasileiras, em grandes ou pequenos municípios. No Rio Grande do Sul, a Polar Export patrocina o Rodeio de Porto Alegre e a Fenachim, tradicionais eventos da cultura gaúcha, além de a Stella Artois ser a marca patrocinadora oficial do Festival de Cinema de Gramado. Em Santa Catarina, o Chopp Brahma patrocina a OktoberFest de Blumenau, maior festa da cerveja no Brasil, além de outras dez festas tipicamente germânicas que ocorrem no mesmo período no estado. Já no Nordeste, a Brahma Fresh patrocina o Circuito de Vaquejadas, que passa por Fortaleza, Natal e outros cinco municípios do Nordeste. Também no Nordeste, mais de dez milhóes de pessoas participam de mais de 300 festas juninas patrocinadas pela Skol, como o tradicional São João de Caruaru (PE) e o São João de Campina Grande. A marca está presente ainda nos carnavais de Recife e Olinda, como patrocinadora oficial das festas há mais de três anos. Por meio das plataformas Skol Folia e Skol Festança, a Skol leva sua marca aos principais eventos de música baiana do país e aos shows sertanejos, buscando estar ainda mais próxima do consumidor por meio da música. A Brahma investe na plataforma country há mais de 30 anos e realiza mais de 200 eventos de rodeio, entre eles os mais famosos: Barretos, Limeira, Americana, Jaguariúna, entre outros. Já a Antarctica aposta no samba e no forró, com o apoio às principais festas regionais. A Bohemia, primeira cerveja do Brasil, é a marca oficial do circuito Comida de Boteco, que acontece em cidades de Minas e algumas capitais, como Goiânia, Rio de Janeiro e Salvador (COMPANHIA..., 2012).

As peças publicitárias das marcas de cerveja veiculadas na mídia televisiva são particularmente especialistas em estabelecer, de forma mais ou menos subliminar, uma estreita relação entre a vivência de determinados conteúdos de lazer, sociais, físico- esportivos, turísticos, especialmente voltados ao público jovem (o encontro no fim de semana, a festa, a praia, as viagens, o barzinho, a balada, o churrasco com os amigos) e o consumo de bebidas alcoólicas, legitimando e banalizando o seu uso.

Estudo desenvolvido por Pinsky (2009, p. 17) aponta a influência direta da propaganda na experimentação e no consumo de bebidas, destacando:

A influência da publicidade no consumo tem, também, uma relação muito mais sutil do que a vontade de ir para o bar logo que se assiste a um comercial. É a imagem que se faz da bebida: a associaçấo entre bebida e bons momentos, alegria, festa, relaxamento, sexualidade, o prazer, a diversão.

Torna-se, portanto, estabelecida a ideia de que sem o consumo de bebidas, especialmente a cerveja, não dá para ser feliz, não há curtição, não é fim de semana nem lazer, e tampouco prazer. Tal noção é reforçada na promoçáo dos grandes eventos patrocinados pelas cervejarias, aproximando diversão e consumo. Skol Sensation, Skol Beach, Skol Folia, Skol Festança, Camarote Brahma Folia, Camarote Brahma Country, entre outros.

Vendrame et al. (2009) avaliam as possíveis relaçóes entre a exposição à publicidade de cerveja e o consumo entre jovens brasileiros e concluem que os mais expostos à propaganda de cerveja 
demonstram ser os que mais apreciam e consomem bebidas alcoólicas em maior quantidade em relação àqueles menos expostos a esse tipo de publicidade.

Pinsky e Silva (1995, p. 119) observam que,

[...] embora a televisão seja o meio de comunicação mais estudado, há também pesquisas realizadas sobre as representaçóes do álcool em filmes, livros, revistas, jornais, letras de música e até cartôes comemorativos.

O estilo de vida e o status prometidos pelo produto anunciados e perseguidos pelo consumidor cedem espaço para novos elementos de sedução para o consumo, pois não se trata mais, segundo Lipovetsky (2007), de consumir para exibir uma posição social, mas sim pela busca imediatista do prazer, com estratégias de sedução que apelam para fatores emocionais.

Ao estudarem a obra de De Grazia, economista que analisou as formas de consumo da sociedade norte-americana, Andrade, Romera e Marcellino (2010, p. 517) destacam:

De Grazia anuncia o referido paradoxo ao salientar que, ainda que o homem possa ser livre para votar, ter acesso a informaçóes, realizar escolhas, ou "fazer o que quiser", essa suposta liberdade mascara o efetivo aprisionamento dos costumes do homem moderno por meio da publicidade.

Mais recentemente, Lipovetsky (2007) destaca o paradoxo da liberdade da sociedade, compreendida como livre pelo direito conquistado pelas escolhas e diversidade de opçóes, mas que é ao mesmo tempo aprisionada pelas condiçóes impostas pelo mercado, pelas amarras da publicidade, valores culturais e pelas frustraçóes que acumula. Desse modo, pode ser citada aqui a apologia do consumo de bebidas presente nos cartazes que tomam conta dos murais das universidades.

\section{Metodologia}

$O$ estudo qualitativo-descritivo foi aqui desenvolvido pela combinação de quadro metodológico composto de pesquisa bibliográfica e documental.

Apresentam-se como documentos de análise o material publicitário na forma de cartaz ou flyers impressos, relacionados a festas destinadas ao público jovem universitário e veiculados em pontos de circulação do referido público, em especial no interior de universidades e em locais próximos.
O critério da coleta do material de análise foi aleatório e marcado pela acessibilidade e disponibilidade da sua aquisição. Os principais pontos de obtenção do material analisado foram nas universidades públicas e particulares do interior do estado de São Paulo, por um período de três anos. Por questóes relacionadas à ética em pesquisa, optou-se por não mencionar o nome das instituiçóes nas quais foram recolhidos os cartazes.

De acordo com Joly (1996), a definição de analisar material publicitário se apresenta como um rico campo para observação das estruturas de produção de sentido pela imagem, uma vez que essa traz consigo forte intenção comunicativa e designada a uma leitura pública. Os cartazes analisados comunicam-se diretamente com o público alvo fazendo uso de cores, imagens, palavras representativas dos principais signos da juventude e aproveitamento de linguagem e cenas da publicidade televisiva de cervejas, especialmente daquelas que se tornaram jargão popular. Em virtude da quantidade de folders coletados, o presente estudo se limitará à discussão e análise do material. Separadamente, um exame mais detalhado das cores e imagens das peças será publicado em estudo futuro. Aqui seráo especialmente avaliados os recursos persuasivos que utilizam a bebida alcoólica como elemento de convencimento para participação em festas, conforme as categorias do grupo $2 \mathrm{da}$ análise.

\section{Análise e discussão}

Compuseram a amostra 173 cartazes publicitários de festas, classificados em dois grupos de análise:

Grupo 1 - Modalidade da festa

a) Festas sem menção a bebidas;

b) Festas open bar com distribuição gratuita de bebidas;

c) Festas com bebidas a preços promocionais.

Grupo 2 - Recurso persuasivo

a) Argumentação verbal;

b) Argumentação imagética.

\subsection{Modalidade da festa}

Nesse primeiro quesito foram classificados três grupos de análise, de acordo com a modalidade da publicidade impressa. O primeiro grupo constituiu $14,1 \%$ do material analisado; o critério para composiçáo desse grupo estava centrado na ausência de qualquer apelo argumentativo, imagético ou verbal, direto ou indireto, relacionado a bebidas alcoólicas. Os argumentos usados nos cartazes faziam alusão 
à festa, anunciavam as bandas musicais e demais atraçóes sem, no entanto, recorrer ao anúncio de bebidas alcoólicas como maneira de convencimento à adesão.

O segundo grupo foi composto de $58,5 \%$ de todo o material e estava relacionado a festas universitárias na modalidade open bar, com distribuição gratuita de bebidas. Essa modalidade de diversão é caracterizada pelo pagamento de um valor único e com o qual se pode consumir bebida à vontade, sem imposição de limite, tanto no que se refere à quantidade quanto no que diz respeito à diversidade oferecida durante o evento. Trata-se de um estilo de festa no qual os participantes têm direito de consumir ao máximo; a adesáo permite o consumo ilimitado de bebidas alcoólicas durante todo o período da festa. A possibilidade de consumo ilimitado anunciado nessa modalidade de festa ratifica o hiperconsumo apontado por Lipovetsky (2007).

Em algumas dessas festas, o primeiro horário é limitado à participação do público feminino, com acesso livre a todas as bebidas, para que depois, somente após uma hora de consumo, o público masculino receba permissão de entrada, também com o direito de consumo ilimitado. Trata-se de uma modalidade de festa open bar denominada first ladies, caracterizada por privilegiar primeiramente o acesso e o consumo de bebida pelas mulheres, fato que por si só já se torna um atrativo para a adesão do público masculino.

O terceiro grupo abarcou $27,4 \%$ dos cartazes. $\mathrm{O}$ argumento de convencimento usado estava relacionado ao valor promocional da bebida, sempre muito abaixo do praticado no mercado. Os cartazes que compuseram esse grupo tinham como principal foco de persuasáo para a adesão ao evento o baixo preço da bebida alcoólica, especialmente da cerveja.

Quando somados os cartazes que compuseram os dois grupos de propaganda de festas que mencionavam bebidas alcoólicas como uma atratividade e recurso argumentativo de convencimento, foi obtido um total de $85,9 \%$ de eventos com essa característica. Em ambas as modalidades, o ponto alto da publicidade estabeleceu estreita relação entre diversão e consumo ou lazer e bebida, de acordo com as afirmaçóes de Bertolo e Romera (2011), Musse (2008), Romera e Marcellino (2010).

Apesar de serem eventos de lazer direcionados ao público jovem, não foi verificado nos cartazes qualquer menção referente a limite de idade para acesso às festas ou idade mínima para compra de convites, sendo completamente ignorada a legislaçáa ${ }^{3}$ que proíbe, para menores de 18 anos, o acesso a esse tipo de ambiente, assim como a venda para e o consumo de bebidas alcoólicas por esse público.

\subsection{Recurso persuasivo}

No segundo quesito analisado, $52,7 \%$ do material apresentava como tema da festa alguma apologia do beber, de modo geral bem-humorado e alusivo a especificidades dos cursos; $32 \%$ se referia a cursos de licenciatura ou bacharelado, conforme os exemplos: "Bebe Direito", "Alconomia", "Administrando a Boca”, "Entorta Bixo". Também foram percebidas frases desafiadoras sobre a resistência à alta ingestão de bebidas: "Não aguenta, bebe leite", "Nós travamos", "Etanóis", "Todo Torto", entre outras.

De maneira geral, a escrita complementava a imagem e vice-versa, compondo quadros imagéticos bem-humorados, relacionando o curso profissional a situaçóes de bebedeira, como uma garrafa de cerveja no lugar de um frasco de soro fisiológico, chamando os alunos "dão" curso de Medicina. Em outra promoção, uma caneca de chope com gravata promovia uma festa para os alunos do curso de Administração. A referência ao curso de Direito é percebida na expressão "Habeas Latas" e, em outra promoção, no símbolo da justiça, a balança, porém, com latas de cerveja representando a sua exatidáo. De acordo com Joly (1996), somos culturalmente iniciados na compreensão das imagens, o que facilita a sua devida identificação, lendo-as como se fossem naturais. E é assim que, com imagens e signos bem-humorados, a participação em festas e no consumo exagerado de bebidas alcoólicas são incentivados pela publicidade aqui analisada.

Ainda como recurso de argumentação verbal foi observado o uso de linguagem veiculada pela publicidade televisiva de cerveja, que, por ser de conhecimento dos espectadores, possibilita uma identificação mais rápida entre o produto (cerveja) e as promessas veiculadas no comercial, tais como "cervejáo" e "churrascão", também num exercício de identificaçáo do público alvo com a festa divulgada.

Também foram mencionados variados estilos musicais de diversas bandas, mas sem relevância para um estilo específico. Todos foram contemplados de modo indistinto, do rock ao sertanejo, seguindo a mesma proposta da realizaçáo de eventos para públicos e gostos diversificados, indo do Carnaval à Vaquejada, conforme divulga o site da AMBEV (COMPANHIA..., 2012), fomentando para si a chance de atingir um universo maior de consumidores ou participantes. 
No que tange à argumentação imagética, as análises recaíram sobre a criação artística dos cartazes, com destaque para as imagens das bebidas. Canecas de chope, copos de caipirinha ou coquetéis, taças com drinques exóticos representaram o recurso empregado em 36\% do material analisado. Imagens de garrafas de bebidas destiladas, com ênfase para o uísque e a vodca, constaram em 31,4\% dos cartazes. As imagens de bebida, fosse no copo, na caneca ou na garrafa, apresentaram-se em consonância com as promoções do evento e foram entendidas como sendo um forte apelo ao consumo, sempre em primeiro plano, em tamanho desproporcional às demais imagens e com cores de destaque. Em alguns cartazes, a garrafa, a lata de cerveja ou a caneca de chope causavam a impressáo de estar saltando do papel, com a festa acontecendo alegremente, como pano de fundo, reforçando imagens de divertimento, supondo a ludicidade e a sociabilidade comuns ao lazer, porém vinculadas ao beber.

De acordo com Musse (2008, p. 7),

Os efeitos da mídia no comportamento humano acontecem de forma cumulativa e gradual. A duração média de um curso universitário é de 4 anos, se em 2 a 3 meses por ano foram vistos 15 tipos de cartazes, a média ao final de quatro anos será de 360 deles, valorizando o uso e abuso de álcool. A tendência é a aceitação disso como certo e natural, promovendo assim dessensibilização quanto aos possíveis prejuízos, favorecendo atitudes imprudentes quanto ao consumo de álcool.

A apologia do consumo de bebidas alcoólicas foi constatada tanto na argumentação verbal quanto na imagética, valendo-se de frases, jargóes e imagens de estímulo ao beber, na naturalização do consumo de bebidas e, em alguns casos, na apologia do beber excessivo.

Em obra de referência para estudos sobre o álcool, Alcohol: no ordinary commodity, Babor et al. (2003) defendem, já no título, não ser o álcool uma mercadoria qualquer; justificam tal afirmativa com dados epidemiológicos e as consequências e agravos do seu uso abusivo, além de proporem, pautados em evidência científica, algumas estratégias de intervençôes com vistas a minimizar os efeitos negativos desse consumo, entre as quais estão destacadas as restrições relativas às estratégias de persuasão de marketing, situação que não se observa no Brasil, especialmente no ambiente das universidades, conforme aqui já apontado.

\section{Considerações finais}

O presente estudo percebeu nos cartazes de festas divulgados nos campi universitários um elevado número de eventos de lazer direcionado ao público jovem cujo principal argumento persuasivo está diretamente relacionado ao consumo de bebidas, com especial destaque para o consumo de cerveja.

Para além da divulgação da festa, percebeu-se o estímulo ao consumo de bebidas, assim como a apologia do beber em excesso como comportamento intrínseco dessa modalidade de lazer.

A oferta de bebida gratuita, a preços mais acessíveis e a possibilidade de consumo ilimitado foram recursos correntes na promoção desse tipo de festa, denominada de open bar, oferecendo a possibilidade de consumo mais intenso, uma vez que abre possibilidades de valores diferenciados para a bebida.

A estreita relação entre beber e o se divertir apresentou-se como um dos principais argumentos persuasivos presentes nos cartazes que promoviam festas para o público universitário, sendo mencionados de forma interligada. Essa associação entre lazer e consumo de bebida é ratificada e fortalecida pelas peças publicitárias com atraentes argumentos verbais e visuais, de caráter sedutor, humorístico ou provocativo, abusando dos signos da comunicação: imagens, cores, palavras, estilos musicais, entre outros.

Apesar da constatação do forte apelo ao consumo excessivo encontrado nos cartazes de promoção de festas para jovens universitários, o presente estudo não pretendeu vincular o constante aumento no número de bebedores com um único aspecto, o lazer, uma vez que o considera fenômeno complexo e multifatorial.

No entanto, o incentivo ao consumo exagerado e naturalizado deve ser alvo de atenção das campanhas de prevenção ao consumo de bebidas, bem como das políticas do álcool, com vistas também à diminuição de apelos que se espalham pelos campi universitários, considerando o rigor que o tema exige.

Este estudo avaliou um aspecto do fenômeno presente na relação entre consumo de bebidas, juventude e lazer, sugerindo mais estudos e aprofundamento. Políticas de prevenção ao consumo de bebidas devem ter como foco a desconstrução da relação estabelecida entre consumo de bebidas e diversão, por meio de mensagens e campanhas que dissociem o lazer do consumo de bebidas, atualmente tấo associados. 


\section{Referências}

ANDRADE, C. P.; ROMERA, L. A.; MARCELLINO, N. C. Contribuiçốes de Sebastian de Grazia para os estudos do lazer. Motriz, Rio Claro, v. 16, n. 2, p. 516-526, 2010.

BABOR, T. et al. Alcohol: no ordinary commodity. Oxford University Press, 2003.

BERTOLO, M. A. Lazer, juventude e as propagandas de cerveja: possibilidade de consumo e prazer. 2011. $92 \mathrm{f}$. Dissertação (Mestrado em Educação Física)-Universidade Metodista de Piracicaba, Piracicaba, 2011.

BERTOLO, M. A.; ROMERA, L. A. Cerveja e publicidade: uma estreita relação entre lazer e consumo. Licere, Belo Horizonte, v. 14, n. 2, p. 1-27, 2011.

BRASIL. Lei ${ }^{\circ}$ 9.503, de 23 de setembro de 1997. Institui o Código de Trânsito Brasileiro. Diário Oficial da República Federativa do Brasil, Brasília, 24 set. 1997. Seção 1, p. 21201.

COMPANHIA DE BEBIDAS DAS AMÉRICAS - AMBEV. Eventos patrocinados. São Paulo; AMBEV. Disponível em: <http://www.ambev.com. $\mathrm{br} / \mathrm{pt}$-br/consumidores/eventos/eventos-patrocinados>. Acesso em: 18 maio 2012.

DUMAZEDIER, J. As drogas e a revolução social do lazer. Licere, Belo Horizonte, v. 6, n. 2, p. 11-19, 2003.

GONZALEZ, E. M.; BUENO, S. M. Programa de prevención de ocio alternativo. Revista Adicciones, Madrid, v. 15, p. 327-346, 2003. Suplemento 2.

INSTITUTO NACIONAL DE CIÊNCIA E TECNOLOGIA PARA POLÍTICAS PÚBLICAS DO ÁLCOOL E OUTRAS DROGAS - INPAD. II Levantamento Nacional de Álcool e Drogas (LENAD). Sáo Paulo: UNIFESP, 2012.

JOLY, M. Introdução à análise da imagem. Tradução de Marine Appenzeller. Campinas: Papirus, 1996.

LIPOVETSKY, G. A felicidade paradoxal: ensaio sobre a sociedade de hiperconsumo. Sáo Paulo: Companhia das Letras, 2007.

MARTINS, R. A. et al. Utilização do Alcohol Use Disorders Identification Test (AUDIT) para identificação do consumo de álcool entre estudantes do ensino médio. Revista Interamericana de Psicologia, Austin, v. 42, n. 2, p. 307-316, 2008.

MUSSE, A. B. Apologia ao uso e abuso de álcool entre universitários: uma análise de cartazes de propaganda de festas universitárias. SMAD Revista Eletrônica Saúde Mental Álcool e Drogas, Ribeirão Preto, v. 4, n. 1, 2008.

NOTO, A. R. et al. Drogas e saúde na imprensa brasileira: uma análise de artigos publicados em jornais e revistas. Caderno de Saúde Pública, Rio de Janeiro, v. 19, n. 1, p. 69-79, 2003.

NUNES JÚNIOR, V. S. Publicidade comercial: proteção e limites na Constituição de 1988. São Paulo: Juarez de Oliveira, 2001.

PINSKY, I. Publicidade de bebidas alcoólicas e os jovens. São Paulo: FAPESP, 2009.

PINSKY, I.; SILVA, M. T. A. As bebidas alcoólicas e os meios de comunicação: revisão da literatura. Revista $A B P$ APAL, São Paulo, v. 17, n. 3, p. 115-121, 1995.

ROMERA, L. A.; MARCELLINO, N. C. Lazer e uso de drogas: a partir do olhar sociológico. Impulso, Piracicaba, v. 20 , n. 49 , p. 75-84, 2010

ROMERA, L. A.; REIS, H. H. B. O uso de álcool, futebol e torcedores brasileiros. Motriz, Rio Claro, v. 15 n. 3, p. 541-551, 2009.

SUÁREZ, J. R.; TOMÁS, E. A.; TOMÁS, M. S. A. Jóvenes, fin de semana y uso recreativo de drogas: evolución y tendências del ocio juvenil. Revista Adicciones, Madrid, v. 15, p. 7-33, 2003. Suplemento 2.

VENDRAME, A. et al. Apreciação de propagandas de cerveja por adolescentes: relaçóes com a exposição prévia às mesmas e o consumo de álcool. Cadernos de Saúde Pública, Rio de Janeiro, v. 25, n. 2, p. 359-365, 2009.

VENDRAME, A.; PINSKY, I. Ineficácia da autorregulamentação das propagandas de bebidas alcoólicas: uma revisão sistemática da literatura internacional. Revista Brasileira de Psiquiatria, São Paulo, v. 33, n. 2, p. 196-202, 2011.

\section{Notas}

${ }^{1}$ O Código de Trânsito Brasileiro (CTB) foi implantado pela lei n. 9.503, de 23 de setembro de 1997, e modificado pela lei n. 11.705, de 19 de junho de 2008, conhecida popularmente como Lei Seca, que inibe o consumo de bebida alcoólica pelo condutor de veículo automotor. Essa nova regulamentação inclui e pode classificar a infração como crime, com pena de reclusão quando a concentraçâo de álcool for superior a 0,6 g/l. (BRASIL, 1997).

${ }^{2}$ A seleção brasileira de futebol, assim como os megaeventos esportivos Copa das Confederaçóes e Copa do Mundo de Futebol, é patrocinada pelas cerveja Brahmas e Budweiser compondo, dessa maneira, mais um paradoxo e contradição de mensagens dirigidas ao público brasileiro.

${ }^{3}$ Brasil. Lei federal n. 8.069, de 13 de julho de 1990. Estatuto dos Direitos da Criança e do Adolescente. Diário Oficial da União, Brasília, DF, Seção 1, 16 jul. 1990. 